\title{
ЭТНОКУЛЬТУРНЫЕ ОСОБЕННОСТИ КАРАЧАЕВО-БАЛКАРСКОЙ ЗАГАДКИ
}

\author{
Б.А. Берберов
}

\begin{abstract}
Актуальность статьи обусловлена тем, что на сегодняшний день загадка является наименее изученным жанром в карачаево-балкарской науке о фольклоре. Как и любой другой фольклорный жанр, загадка, помимо универсальной основы, имеет и этнически маркированные черты, предопределенные факторами географического и исторического порядка. Собранный за период с 1909 г. по 2011 г. усилиями зарубежных и отечественных этнографов эмпирический материал (свыше 1500 единии) до сих пор не подвергнут комплексному научному осмыслению. Научная новизна статьи заключается в том, что в ней впервые исследуются этнокультурно обусловленные особенности карачаево-балкарской загадки. Основная иель - с опорой на теорию Г.Д. Гачева о Космо-Психо-Логосе выявить и описать те конкретные поэтологические слагаемысе, которые составляют онтологическую сущность национальной загадки. Для решения поставленной задачи в работе используются следующие методы исследования: сравнительно-исторический, системно-структурный, семиотический, а также типологизация, классификация, обобщение. Согласно полученным результатам, этнокультурная специ бика рассмотренных загадок в первую очередь определяется императивом горного ландшафта, продуцирующим большое количество оронимов (гора, холм, скала) для характеристики человека и окружающих его предметов. Во вторую очередь практически все анималистические и вегетативные образы в национальных загадках отмечены знаком «эндемичности", то есть они географически привязаны к Северному Кавказу. Кроме того, значительное число загадок основано на кониептуализации древних обычаев, традиции, обрядов, вследствие чего архаизмы и историзмы продолжают использоваться в речи.
\end{abstract}

Ключевые слова: этнокультура, карачаево-балкарская загадка, оронимы, зооморфные образы, вегетативная кодификация, мифологема, архаизм.

Затрагивая проблемы гносеологии, литературовед Н.А. Шогенцукова в своей монографии «Опыт онтологической поэтики» пишет: «Познание - одна из высших целей и отдельного человека, и всего человечества. В системе познания выделяются проблемы, которые являются основополагающими. Их решал и решает род человеческий на протяжении тысячелетий: в чем смысл и предназначение существования индивида и многих поколений; кто мы, откуда и куда идем; что есть мир, жизнь, смерть, космос, любовь, красота? В философии этот круг проблем, получивший определение вечных вопросов бытия, образовал свою область - онтологию. Идут к ответам на эти вопросы по-разному» $[1,3]$.

Одним из действенных способов познания мира является загадка древнейший фольклорный жанр, который «содействует активизации познания окружающего мира, фор- 
мирует навыки логического мышления, развивает наблюдательность» $[2,273]$.

История сбора, систематизации и публикации карачаево-балкарских загадок насчитывает более ста лет. Впервые их ввел в научный оборот венгерский ученый В. Прёле, опубликовав в 1909 г. в журнале «Keleti Szemle» карачаевские [3, 307], а в 1916 г. балкарские загадки $[3,377]$ наряду с другими образцами горского фольклора. Научные изыскания В. Прёле в дальнейшем были продолжены фольклорно-лингвистической экспедицией КБНИИ 1939 г. [4], С.У. Алиевым [5], Т.М. Хаджиевой [6], Т.Ш. Биттировой и А.Б. Габаевой [7], М.М. Ольмезовым [8], Р.А.-К. Ортабаевой [9].

В свое время отечественный культуролог, философ и литературовед Г.Д. Гачев установил закон соотнесенности между местом проживания народа, его темпераментом и системой логического мышления. Автор пишет: «Искомую национальную целостность я определяю как Космо-Психо-Логос. Подобно тому, как каждое существо есть троичное единство: тело, душа и дух, - так и всякая национальная целостность есть единство местной природы (Космос), характера народа (Психея), склада мышления (Логос). В Космо-Психо-Логосе три элемента (уровня) национальной целостности находятся в отношении и соответствии (тождества друг другу) и взаимной дополнительности (противоположности и уравновешивания) $[10,34]$.
С этой точки зрения особый научный интерес представляют карачаево-балкарские загадки. Прежде всего, отметим, что загадка, как и любой другой фольклорный жанр, является двухполюсным явлением, поскольку содержит в себе как универсальные, общечеловеческие структурные компоненты, так и национально-маркированные, которые являются предметом нашего исследования.

Карачаевцы и балкарцы - единокровный народ, испокон веков проживающий на склонах и у подножья Кавказских гор. Недаром даже самоназвание народа содержит в себе семантическое ядро таулу, что в переводе означает «горец». Естественно, географическая сущность этой категории «проецируется и на область быта, морали, культуры, духа» [11, 44].

Детерминация карачаево-балкарских загадок этническим фактором начинается с самого жанрового обозначения загадки на родном языке - элбер. Это коротенькое двухкорневое слово в конденсированном виде содержит в себе понятие - «то, за что дают селения». На самом деле, в архаичные времена в горской культуре игра в загадки переставляла собой настоящий интеллектуальный церемониал. Чаще всего играли зимними вечерами в свободный от сельскохозяйственных дел промежуток времени. В каждом этноколлективе, ауле был общепризнанный ведущий, как правило, более других образованный и просвещенный человек, обладающий копилкой зара- 
нее заготовленных загадок. Наряду с этой копилкой им был припасен и список названий различных аулов, сел и городов под "раздачу» в качестве призов для местных "умников» и «умниц». За каждую отгаданную загадку участник игры «получал» определенный населенный пункт, тем самым расширяя свою условную территорию. Нередко были случаи, когда игроки, ответившие на вопрос повышенной сложности, старались «выторговать» себе не просто какой-то захолустный соседний аул, но крупный восточный город, наподобие Багдада или Стамбула.

Сразу возникает вопрос: почему в качестве награды за высокий интеллект, сообразительность и смекалку северокавказские горцы предпочитали для себя участок земли, территорию, сотки, гектары? Естественно, для малоземельного или безземельного крестьянина, который долбит на склонах горы гранитный камень, таскает ведрами почву с равнинных мест наверх и лепит террасный огородик или садик, не существует большей ценности, чем территориальный прирост. Хотя бы в мечтах, хотя бы в рамках интеллектуальной игры. На наш взгляд, именно эти социально-экономические чаяния северокавказских горцев нашли отражение в фольклорно-жанровой номинации элберле - «дающие села (города)». Самый полный свод национальных загадок составлен карачаевским исследователем С.Ч. Алиевым, в чей сборник включено 1350 фольклорных единиц. К этим классическим загадкам составитель добавил еще
68 загадок в форме прямых вопросов (соруула), 5 юмористических загадок (чамла), 12 арифметических головоломок (эсебле), а также 12 нарративных загадок (хапар джомакъ). Рассуждая о тематическом диапазоне карачаево-балкарских загадок, Алиев пишет: «Складывается впечатление, что народ сочинил загадки обо всем, что видят глаза, держат руки - от космоса до соломинки, от человека до муравья» $[5,18]$.

Весь собранный карачаевским этнографом материал подразделен на 25 больших разделов, которые, в свою очередь, дробятся на еще более мелкую, детализированную рубрикацию. К примеру, раздел «животные» делится еще на два подраздела - «дикие» и «домашние». Другие достоинства алиевского сборника - внимание к диалектным версиям загадок и снабжение многочисленных архаизмов научными комментариями.

В статье на материале этнокультурно маркированных загадок предполагается воссоздание основных контуров карачаево-балкарской картины мира. По загадкам можно многое узнать о карачаево-балкарском Космо-Психо-Логосе: как человек воспринимал самого себя, во что он одевался, какой посудой пользовался, чем питался, что выращивал, как выглядел его сельхозинвентарь, что составляло суть контекстуально близкой ему «флоры» и «фауны», как он трактовал погодные явления, что его радовало, что огорчало, имелись ли у него представления о космосе и космических телах? Не менее важен 
и вопрос, связанный с определением статики и динамических процессов относительно предметно-персонажного мира в национальных загадках.

По нашим наблюдениям, при метафоризации загадок архаичный карачаево-балкарец чаще всего прибегает к концептам «гора» и «скала», то есть самым крупным и важным природным объектам в его окружении. Ниже приведем загадку, где горец самого себя (или голову) представляет в форме горы, а волосы - в виде густого леса: Тау башында - къара агъач. (Чач) [5, 37]. - На горе - черный лес. (Волосы) (Здесь и далее все переводы автора статьи).

«Природина» (выражение Г.Д. Гачева), то есть родной ландшафт, является определяющим в любом случае, даже если речь идет о предметах, далеких от орографии. К примеру, вот как описывается в загадке процесс стрижки человеческих волос:

Сьртда отун томурула, джонгурчхасы тюзге тюше. (Баш днюлюген) [5, 43]. - На холме рубят лес. Щепки сыплются на равнину. (Стрижка головы).

Из этой же серии загадка про «пот, испарину» - «Ала тауну суу mарай» [5, 40]. - (Со светлой горы река течет), а также про «слезу» «Сьртдан къыпnа тёнгерер» $[5,40]$. - (Со склона горы клубок катится).

Все процессы питания человека, начиная с охотничьего промысла и завершая кухонной утварью, также чаще всего оказываются метафоризированными посредством орографических образов. Народ, в жизни которого охота играла громадную жизнеобеспечивающую роль, сочинил следующую загадку: Экеулен таудан келе, бешеулен аллына келе. (Ашагъан) [5, 49]. - Двое с гор спускаются, пятеро навстречу идут. (Еда). Под «двумя» здесь подразумевается охотник с добычей, а «пятеро» - это условное обозначение семьи, ожидающей своего кормильца.

Яйцо - один из архетипических образов в мировой культуре, имеющий множество иносказательных характеристик в разных языках. Горцы Северного Кавказа с их склонностью использовать оронимы своеобразно суть «яйца» зашифровывают в загадке: Ары джаны - акъ къая, бери джаны - акъ къая, ортасында - сарь мая. (Гаккы) $[5,56]$. - С одной стороны - белая скала, с другой стороны - белая скала, а в середине - желтая масса. (Яйцо).

Плотность и цвет яичной скорлупы, напоминающей скальные породы, интересует горцев гораздо больше, чем ее круглая форма или функциональные особенности. Типологически сходный метод концептуализации отмечен и в следующей загадке, где речь идет о хлебе внутри сковородки: Эки къара къая, ортасында - толгъан ай. (Таба гырджын) $[5,52]$. - Две черные скалы, посередине - полная луна. (Хлеб на сковороде).

При иносказательном воспроизведении какого-либо предмета национальной одежды народная фантазия также прибегает к знакомым образам горного края. Это касается таких предметов, как башлык, тулуп, серебряный пояс, бурка, шерстяные 
носки, кафтан, рукавицы, перчатки, ноговицы. Вот один из примеров: Тёгереги къала, ортасы - тала. (Бухар бёрк) [5, 79]. - Вокруг - крепость, в середине - равнина. (Бухарская шапка).

Как для архаичных, так и современных хозяек свойственно надевать фартук при выполнении кухонно-хозяйственных дел. Тренированный глаз горца даже эту утилитарную композицию «передняя часть человеческого тела - cop - защита» мгновенно переводит в метафорический комплекс с ядерным концептом «гора»: Бир джабыуум барды да, Таугъа букъу къондурмайды. (Хота) $[5,82]$. - У меня есть покрывало, оно гору защищает от пыли. (Фартук).

Создается впечатление, что в сознании горца изначально имеется определенная «горная модель», которую можно приложить к любому субъекту или объекту действительности, независимо от его размера. Казалось бы, что общего между женскими серьгами на ушах и «горным комплексом», но и здесь вертикальная ритмика выступает в качестве определяющего фактора: Таугъа минселе, тагъыла, таудан тюшселе, джыгъыла. (Алтын сыргъала) [5, 83]. - На гору взбираются - крепятся, с горы слезают - падают на бок. (Золотые серьги).

Второе место по частности в карачаево-балкарских загадках занимает зооморфная тематика. Экономическую основу жизнедеятельности северокавказских народов составляет животноводство. По загадкам можно определить, что в ближний круг карачаевцев и балкарцев входят такие домашние животные, как корова, конь, овца, коза, вол, бык, ослик, мул, кошка, собака; из птиц - курица, гусь, утка, индюк, цыпленок.

Без внимания не остаются и представители дикой природы волк, лиса, заяц, ёж, лось, косуля, медведь, тур, кукушка, орел, ворона. Кроме кавказских эндемиков, в тематическое поле национальной загадки попадают и такие экзотические животные, как лев, тигр, крокодил, слон, верблюд. Следует сказать о том, что зооморфные образы в национальных загадках исполняют двоякую роль: а) выступают как изображаемые, определяемые объекты; б) выполняют серверную роль при метафорическом уподоблении двух разносистемных предметов:

Анасындан мыцйыкълары бла туугъан бетин-къолун сапьнсыз-суусуз джуугъан (Киштик) [5, 178]. - От матери родившийся с усами без мыла, без воды умывается. (Кошка);

Бир къызым барды да, ийнели чепкен киеди. (Кирпи) [5, 180]. - Есть у меня одна дочь, игольчатое платье носит. (Ежик);

Не анасы табмагъан, не атасы табмагъан. (Джюджек) [5, 187]. - Ни матерью не рожден, Ни отцом не рожден. (Цыпленок).

Из другой области приведем несколько примеров, когда образы животных используются не в прямом, а переносном смысле для завуалированной характеристики предметов материального мира или погодно-климатических явлений: 
Къарангы бауда - акъ къозула. (Тишле) [5, 38]. - В темном сарае белые ягнята. (Зубы);

Бир аркъанда - минг джылкъы. (Мьнчакъла) [5, 84]. - На одном аркане тысяча лошадей. (Бусы);

Дорбун толу - къарабаш къозу. (Сернекле) [5, 99]. - Пещера полна черноголовых ягнят. (Спички);

Уя этеди да, ичинде турмайды. (Буруу) [5, 120]. - Вьет себе гнездо, но сам там не живет. (Сверло);

Съцттда къой кесиле, лъань бери келе. (Ырхы) [5, 144]. - На холме барана режут, кровь вниз стекает. (Cелевой поток).

Исключительно важное место в карачаево-балкарских загадках принадлежит также флоре - деревьям, кустарникам, травам, цветам. В древности деревья обожествлялись на Северном Кавказе: достаточно вспомнить священные деревья Жангъıз Терек (Одинокое Дерево) [12, 231] в Карачае и Раубазы в Балкарии [12, 232], которым в доисламскую эпоху горцы-язычники поклонялись, к подножию возлагали всевозможные дары, обращались к «зеленому божеству» с просьбами. Сама жизнь вынуждала архаичного горца хорошо разбираться в травах, различать съедобное от несъедобного, поскольку коренья, стебли, листья полевых растений составляли значительную часть его рациона. С ходом цивилизационного развития сады и огороды горцев пополняются новыми сортами плодоовощных культур - в этих краях появляются ранее неизвестные помидоры, огурцы, баклажаны, капуста и др. Естественно, все эти дары природы в виде вегетативных образов народной фантазией широко используются в национальных загадках.

Как и в случае с анималистическими образами, флористические единицы играют амбивалентную роль в загадках, выступая и как номинируемый объект, и как средство иносказательной номинации. В этом плане особенно востребованным стал смыслоемкий архетипический образ «дерево», который, благодаря своим структурным компонентам «ветки», «корни», «плоды», оказался весьма удобен для обозначения самых разных реалий. Приведем несколько примеров:

Бир терекде - беш бутакъ, беш бутакъда - беш чапракъ. (Бармакъла, тырнакъла) [5, 36]. - На одном дереве - пять ветвей, на каждой ветке - пять листочков. (Пальцы, ногти);

Къара чегетде - акъ терек. (Чал тюк) $[5,37]$. - В темном лесу - белое дерево. (Седой волос).

Вторую часть флористических загадок составляют структурные модели, побуждающие слушателя (читателя) отгадать зашифрованный природный объект. В полном соответствии с гачевской теорией Космо-Психо-Логоса «героями» карачаево-балкарских загадок являются растения, хорошо знакомые горцам - овес, пшеница, просо, ячмень, рис, пшено, гречка, картошка, кукуруза, шиповник, ель, сосна, вишня, яблоня, груша, слива, смородина, подсолнух, кизил, чинар, абрикос и т.д. По нашему наблюдению, большинство 
эстетически привлекательных растений в загадках представлены завуалированными под женский образ. Вот несколько примеров:

Бир къызым барды да, джылына джети чепкен киеди. (Нартюх) [5, 152]. - У меня есть одна дочь, в год семь платьев одевает. (Кукуруза);

Эки эгечни: бири къызыл кие, бири къара кие. (Къьзыл дугъум бла къара дугъум) [5, 157]. - Из двух сестер одна в красное одевается, другая - в черное. (Красная и черная смородина.)

При знакомстве с комплексом вегетативных загадок складывается впечатление, что посредством их старшее поколение передает свой жизненный опыт молодым, знакомит детей с основами народной медицины. К примеру, важный поучительный смысл содержится в загадке о столь ценной лечебной траве, как подорожник: Бир кючюгюм бардь да, джараланы джалайдь. (Иттил чапракъ) $[5,160]$. - У меня есть один щенок, Он лижет (лечит) раны. (Подорожник).

На многие травы карачаево-балкарский народ смотрит с точки зрения земледельца, заготавливающего сено. Традиционно косари весьма чувствительно относятся к скашиваемой траве, тонко различают мягкость и плотность стебля. У них задача - не только заготовить как можно больше сена, но и сберечь в целости и сохранности нежное лезвие своего рабочего инструмента - косы. Вот одна из коротеньких, но емких загадок, где концептуализируется такое растение, как перезрелая сурепка, чьи жесткие стебли досаждают косарям: Биченликде - кючлю къатын. (3ыка) [5, 160]. - На покосе - могучая баба. (Сурепка).

Любопытным средоточием карачаево-балкарского взгляда на природный объект является загадка-четверостишие о подсолнухе, в котором сошлись несколько народных онтологических детерминант гора, овца, растение, спаянных единым полисемантическим полем:

Мийик-мийик мийик тау, миц̆ик тауда - бир тала, бир талада - минг къой, миингиси да - къара. (Чёплеу табакъ) [5, 170]. - Высоко-высоко высокая гора, на высокой горе - одна поляна, на этой поляне - тысяча овец, все тысячи - черные. (Головка подсолнуха).

Этнокультурные особенности карачаево-балкарской загадки еще проявляются в ее апелляции к всевозможным фольклорным, мифологическим мотивам, традициям, обрядам и обычаям. В большинстве случаев этот уходящий мир национальной старины без обращения к специальным источникам может быть и непонятен, особенно молодым читателям. Приведем пример такой архаической загадки: Чалкъы ььзда - къьзылкёз теке. (Акъсакъал) $[5,45]$. - На покосе - красноглазый козел. (Аксакал).

В обыденном сознании под «аксакалом» (тюрк. «белая борода») принято подразумевать старого, мудрого человека, убеленного сединой. Но, как выясняется, в приведенной загадке замаскирована совсем другая фигура, сведения о ко- 
торой можно почерпнуть из «Карачаево-балкарско-русского словаря» [13]. Оказывается, это «персонаж народного театра в период сенокоса; он надевает маску из войлока со всевозможными украшениями и развлекает косарей шутками и танцами и т.п. В руке у него мешок с подарками за игры, развлечения, а потом он их раздает девушкам, молодым косарям» $[13,43]$ как стимулирующую добавку за труд.

В сборнике С.Ч. Алиева зафиксирован и перечень современных, инновационных загадок, посвященных таким артефактам, как бульдозер, автомобиль, телефон, самолет и т.п. Этот факт показы- вает, что процесс познания мира посредством фольклорных жанров продолжается.

На основании исследованного материала можно сделать вывод о том, что карачаево-балкарская загадка является интересной и самобытной фольклорной субкультурой, отмеченной ярко выраженным национальным колоритом, который главным образом проявляется через мировоззренческий уровень. Суть этого уровня определяют мыслительные координаты северокавказского горца, детерминированные окружающей природой, историческими условиями и мифологическим наследием народа.

1. Шогенцукова Н.А. Опыт онтологической поэтики. М.: 1995.

2. Литературная энциклопедия терминов и понятий / Гл. ред. и сост. А.Н. Николюкин. М., 2003.

3. Прёле В. Карачаевские тексты. Загадки // Карачаево-балкарский фольклор в дореволюционных записях и публикациях / Сост., вступ. ст. и коммент. А.И. Алиевой. Нальчик, 1983.

4. Материалы и исследования по балкарской диалектологии, лексике и фольклору. Нальчик, 1962.

5. Алиев С.Ч. Къарачай халкъны эл берген джомакълары (Карачаевские народные загадки). Черкесск, 1984. (на кар.-балк. яз.)

6. Къарачай-малкъар фольклор (Карачаево-балкарский фольклор). Хрестоматия / Сост., вступ. ст. Т.М. Хаджиевой. Нальчик, 1996. (на кар.-балк. яз.)

7. Алгъышла, нарт таурухла, жомакъла, жырла, элберле... (Пожелания, легенды о нартах, сказки, песни, загадки...): Хрестоматия по карачаево-балкарскому фольклору / Сост. Т.М. Биттирова, А.Б. Габаева. Нальчик, 1997. (на кар.-балк. яз.)

8. Къарачай-малкъар ойберле бла элберле (Карачаево-балкарские притчи и загадки) / Сост. М.М. Ольмезов; Переводы с кар.-балк. Х.Ч. Джуртубаева. Нальчик, 2010. 
9. Ортабаева Р.А.-К. Карачаево-балкарские народные загадки (Къарачай-малкъар халкъны эл берген джомакълары) // Загадки народов Карачаево-Черкесии: Оригиналы и переводы на русский язык. Черкесск, 2011. C. 83-124.

10. Гачев Г.Д. Ментальности народов мира. М., 2003.

11. Кучукова 3.А. Нартский эпос: вертикаль как метакод бытия // Культурная жизнь Юга России. 2005. № 4. С. 44-48.

12. Джуртубаев М.Ч. Древние верования балкарцев и карачаевцев: Краткий очерк. Нальчик, 1991.

13. Къарачай-малкъар орус сёзлюк (Карачаево-балкарско-русский словарь) / Под ред. чл.-корр. АН СССР Э.Р. Тенишева и к.ф.н. Х.И. Суюнчева. М., 1989.

Berberov, Burkhan A. - Institute for Humanitarian Researches of the KabardinBalkar Scientific Center of RAS (Nalchik, Russia); burhan_berberov@mail.ru

\section{ETHNOCULTURAL FEATURES OF THE KARACHAY-BALKAR RIDDLE.}

Keywords: ethnoculture, Karachay-Balkari riddle, oronyms, zoomorphic images, vegetative codification, mythologeme, archaism.

The relevance of this article is due to the fact that today the riddle is the least studied genre in the Karachay-Balkar science of folklore. Like any other folklore genre, the riddle, in addition to its universal basis, also has ethnically marked features, predetermined by factors of a geographical and historical order. The empirical material (over 1500 units) collected from 1909 to 2011 by the efforts of foreign and domestic ethnographers has not yet been subjected to comprehensive scientific comprehension. The scientific novelty of the article lies in the fact that the author for the first time explores ethnoculturally determined features of the KarachayBalkar riddle. The main goal is based on the theory of G.D. Gachev on the cosmo-psycho-logos to identify and describe those specific poetological terms that make up the ontological essence of the national riddle. To solve this problem, the following research methods are used in the work: comparative-historical, system-structural, semiotic, as well as typologization, classification and generalization. According to the results obtained, the ethnocultural specificity of the considered riddles is primarily determined by the imperative of the mountain landscape, which produces a large number of oronims (mountain, hill, rock) to characterize a person and the objects around him. Secondly, almost all animalistic and vegetative images in national riddles are marked with the sign of "endemicity", that is, they are geographically tied to the North Caucasus. In addition, a significant number of riddles are based on the conceptualization of ancient customs, traditions, rituals, as a result of which archaisms and historicisms continue to be used in speech.

\section{REFERENCES}

1. Shogentsukova, N.A. Opyt ontologicheskoi poetiki [Experience of ontological poetics]. Moscow, Nasledie, 1995. 232 p.

2. Nikolyukin, A.N. (ed., comp.) Literaturnaya entsiklopediya terminov $i$ 
ponyatii [Literary encyclopedia of terms and concepts]. Moscow, Intelvak, 2003. 1596 columns.

3. Pröhle, W. Karachaevskie teksty. Zagadki [Karachay texts. Riddles]. Karachaevo-balkarskii fol'klor $v$ dorevolyutsionnykh zapisyakh i publikatsiyakh [Karachay-Balkarian folklore in pre-revolutionary records and publications]. Nalchik, El'brus, 1983. 432 p.

4. Materialy $i$ issledovaniya po balkarskoi dialektologii, leksike i fol'kloru [Materials and research on Balkarian dialectology, vocabulary and folklore]. Nalchik, Kabardino-Balkarskoe knizhnoe izdatel'stvo, 1962. 200 p.

5. Aliev, S.Ch. K"arachai khalk"ny el bergen dzhomak"lary (Karachaevskie narodnye zagadki) [Karachay folk riddles]. Cherkessk, Stavropol'skoe kn. izd-vo (Karachaevo-Cherkesskoe otd.), 1984.216 p. (in Karachay-Balkarian)

6. Khadzhieva, T.M. (comp.) K"arachai-malk"ar fol'klor (Karachaevo-balkarskii fol'klor). Khrestomatiya [Karachay-Balkar folklore. Chrestomathy]. Nalchik, El'Fa, 1996. 592 p. (in Karachay-Balkarian)

7. Bittirova, T.M., Gabaeva, A.B. (comps) Alg"yshla, nart taurukhla, zhomak"la, zhyrla, elberle... (Pozhelaniya, legendy o nartakh, skazki, pesni, zagadki...). Khrestomatiya po karachaevo-balkarskomu fol'kloru [Wishes, legends about the Narts, fairy tales, songs, riddles... Chrestomathy on Karachai-Balkar folklore]. Nalchik, El'brus, 1997. 344 p. (in Karachay-Balkarian)

8. Olmezov, M.M. (comp.) K"arachai-malk"ar oiberle bla elberle (Karachaevobalkarskie pritchi i zagadki) [Karachay-Balkarian parables and riddles. Transl. from Karachay-Balkarian by Kh.Ch. Dzhurtubaev]. Nalchik, El'brus, 2010. 456 p.

9. Ortabaeva, R.A.-K. Karachaevo-balkarskie narodnye zagadki (K"arachaimalk"ar khalk"ny el bergen dzhomak"lary) [Karachay-Balkarian folk riddles]. Zagadki narodov Karachaevo-Cherkesii. Originaly i perevody na russkii yazyk [Riddles of the peoples of Karachay-Cherkessia. Originals and translations into Russian]. Cherkessk, Karachay-Cherkessian Institute for Humanities, 2011, pp. 83-124.

10. Gachev, G.D. Mentalnosti narodov mira [The mentalities of the peoples of the world]. Moscow, Eksmo, 2003. 544 p.

11. Kuchukova, Z.A. Nartskii epos: vertikal' kak metakod bytiya [Nart epic: vertical as a metacode of being]. Kulturnaya zhizn' Yuga Rossii [Cultural life of the South of Russia]. 2005, no. 4, pp. 44-48.

12. Dzhurtubaev, M.Ch. Drevnie verovaniya balkartsev i karachaevtsev: Kratkii ocherk [Ancient Beliefs of Balkars and Karachais: A Brief Essay]. Nalchik, El'brus, $1991.256 \mathrm{p}$.

13. Tenishev, E.R., Suyunchev, Kh.I. (eds) K"arachai-malk"ar orus sezlyuk (Karachaevo-balkarsko-russkii slovar') [Karachay-Balkar-Russian dictionary]. Moscow, Russkii yazyk, 1989. 832 p. 